\title{
Repair technique for a rare partial anomalous pulmonary venous return associated with retroaortic innominate vein
}

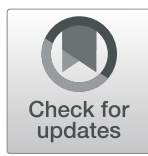

\author{
Hanna Jung, Joon Yong Cho and Youngok Lee* ${ }^{*}$
}

\begin{abstract}
Background: Retroaortic innominate vein (RIV) is a rare vascular abnormality. Although RIV itself is asymptomatic, its presence in patients with partial anomalous pulmonary venous return (PAPVR) to the superior vena cava (SVC) is surgically challenging because a simple Warden procedure is impossible.

Case presentation: A 16-year-old girl was diagnosed with tetralogy of Fallot, secundum, and sinus venosus atrial septal defect (ASD) at birth. She underwent total correction of tetralogy of Fallot and ASD closure at the age of 14months. However, the diagnosis of PAPVR was missed. At the age of 16, she developed dyspnea on exercise. Echocardiography demonstrated severe pulmonary regurgitation, mild tricuspid regurgitation, and D-shaped left ventricle with paradoxical septal motion along with RIV and sinus venous ASD. Computed tomography confirmed RIV and PAPVR. Systemic and pulmonary venous blood pathways were separated by bovine pericardial patch, and pulmonary valve replacement was performed. Postoperative echocardiography demonstrated improvement of Dshaped left ventricle and laminar flow through the SVC and pulmonary veins. Postoperative computed tomography showed a well-reconstructed SVC and pulmonary venous pathway without stenosis. After an uneventful postoperative course, patient was discharged.
\end{abstract}

Conclusions: PAPVR in patients with RIV may be surgically challenging to repair. We report the first case of successfully repaired PAPVR associated with RIV.

Keywords: Congenital heart disease, Partial anomalous pulmonary venous return, Retroaortic innominate vein

\section{Background}

Retroaortic innominate vein (RIV) is a rare vascular anomaly, usually associated with tetralogy of Fallot (TOF), pulmonary artery hypoplasia, and right aortic arch [1]. In partial anomalous pulmonary venous return (PAPVR), some pulmonary veins (PVs) drain either into the systemic venous circulation or directly into the right atrium instead of the left atrium (LA). This causes a physiologic left-to-right shunt that can have various presentations [2, 3]. Although RIV does not cause

\footnotetext{
* Correspondence: yolee1210@knu.ac.kr

Department of Thoracic and Cardiovascular Surgery, Kyungpook National University Hospital, Kyungpook National University School of Medicine,

41944, 130 Dongdeok-ro, Jung-gu, Daegu, Republic of Korea
}

symptoms by itself, its presence in patients with PAPVR with drainage into the superior vena cava (SVC) is surgically challenging because a simple Warden procedure is impossible. Here, we present a successfully repaired PAPVR associated with RIV.

\section{Case presentation}

A 16-year-old girl was diagnosed with TOF, secundum, and sinus venosus atrial septal defect (ASD) at birth. Additionally, she had Turner syndrome [46, X, $\operatorname{del}(\mathrm{X})(\mathrm{p} 11.2)]$ and a horseshoe kidney. She underwent total correction of TOF and ASD closure at the age of 14-months, including patch closure of the subarterial ventricular septal defect, direct closure of the ASD,

(c) The Author(s). 2021 Open Access This article is licensed under a Creative Commons Attribution 4.0 International License, which permits use, sharing, adaptation, distribution and reproduction in any medium or format, as long as you give appropriate credit to the original author(s) and the source, provide a link to the Creative Commons licence, and indicate if changes were made. The images or other third party material in this article are included in the article's Creative Commons licence, unless indicated otherwise in a credit line to the material. If material is not included in the article's Creative Commons licence and your intended use is not permitted by statutory regulation or exceeds the permitted use, you will need to obtain permission directly from the copyright holder. To view a copy of this licence, visit http://creativecommons.org/licenses/by/4.0/ The Creative Commons Public Domain Dedication waiver (http://creativecommons.org/publicdomain/zero/1.0/) applies to the data made available in this article, unless otherwise stated in a credit line to the data. 
resection of the infundibular muscle, and transannular patch extending to the main pulmonary artery. However, the diagnosis of PAPVR was missed. She was doing well at her annual outpatient clinic follow-up. At the age of 16, she developed dyspnea on exercise. Echocardiography demonstrated severe pulmonary regurgitation, mild tricuspid regurgitation, and D-shaped left ventricle (LV) with paradoxical septal motion along with RIV and sinus venous ASD. Computed tomography also confirmed RIV and PAPVR (Fig. 1). The right upper pulmonary vein (RUPV) drained into the SVC and the right middle pulmonary vein (RMPV) showed dual drainage into the SVC and LA. Surgical repair of PAPVR, sinus venous ASD, and pulmonary regurgitation was planned.

Redo-median sternotomy and bicaval venous cannulation were performed. SVC cannulation was performed with a $20 \mathrm{Fr}$ angle catheter at the utmost distal SVC above the anomalous PV and RIV. Under mild
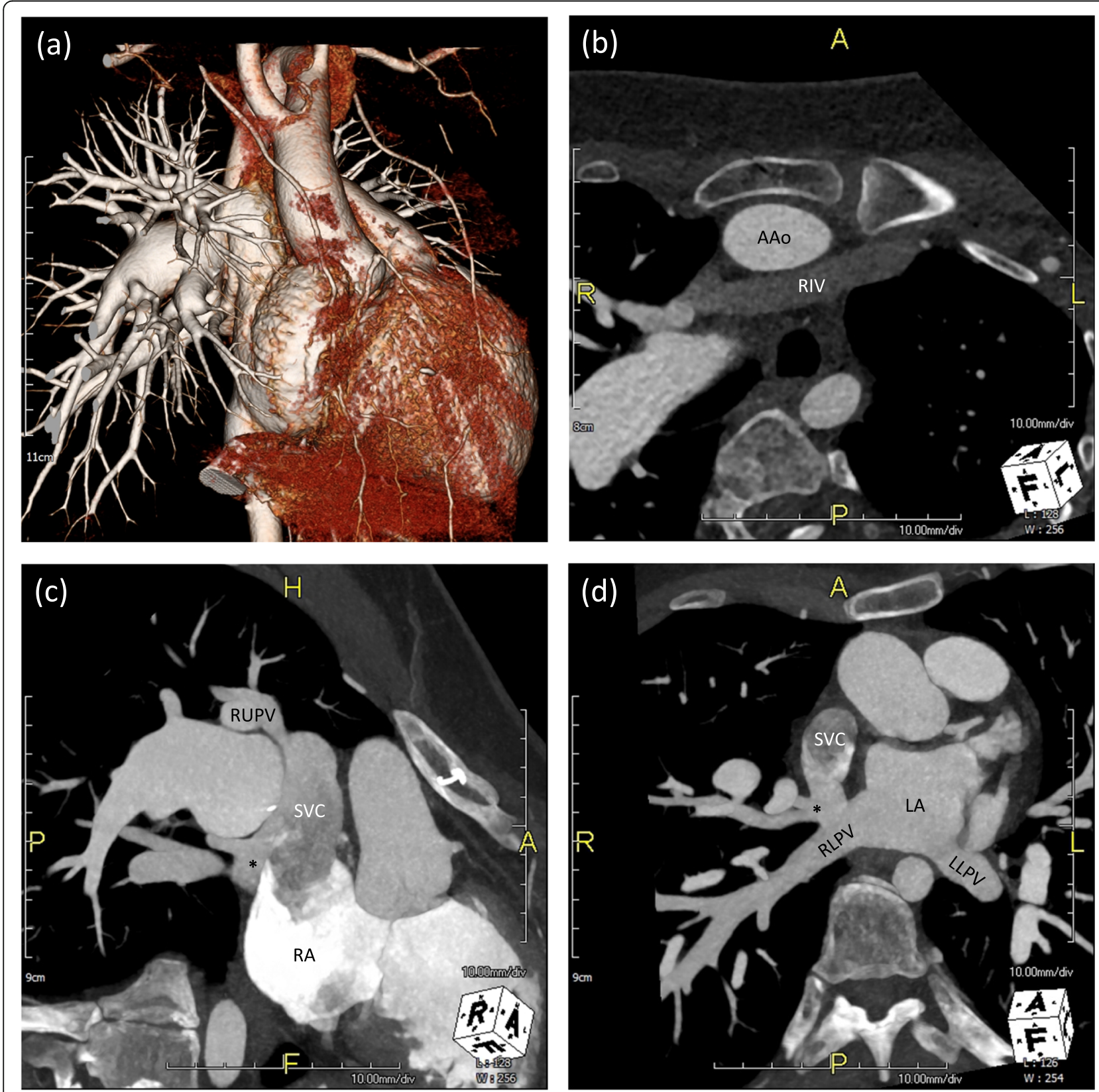

Fig. 1 Preoperative chest computed tomography with (a) 3-dimensional reconstruction. Computed tomography demonstrating (b) RIV, (c) anomalous connection of RUPV and RMPV (asterisk) to SVC, and (d) dual connection of RMPV (asterisk) to SVC and LA. AAo, ascending aorta; RIV, retroaortic innominate vein; RUPV, right upper pulmonary vein; RMPV (asterisk), right middle pulmonary vein; SVC, superior vena cava; RA, right atrium; LA, left atrium; RLPV, right lower pulmonary vein, LLPV, left lower pulmonary vein 

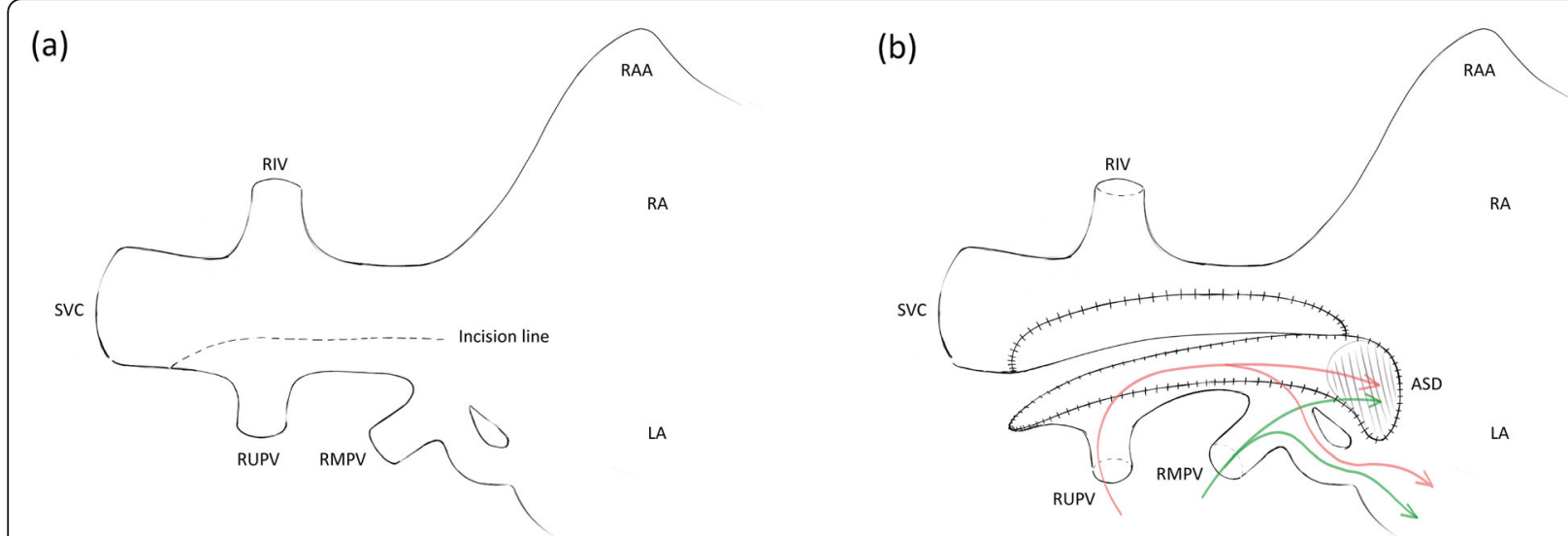

Fig. 2 Image illustration of repair technique. (a) Lateral wall of SVC was incised from just above the junction of anomalous connection of RUPV to just below the junction of anomalous connection of RMPV. (b) Systemic and pulmonary venous blood pathways were separated by bovine pericardial patch. Creating dual pulmonary venous blood flow; RUPV and RMPV drained directly or through intra-atrial tunnel and sinus venous ASD into LA. SVC, superior vena cava; RIV, retroaortic innominate vein; RUPV, right upper pulmonary vein; RMPV (asterisk), right middle pulmonary vein; RAA, right atrium appendage RA, right atrium; LA, left atrium; ASD, atrial septal defect

hypothermia cardiopulmonary bypass and after pharmacological cardiac arrest, the lateral wall of the SVC was incised from just above the junction of the anomalous RUPV to just below the junction of anomalous RMPV (Fig. 2a). Systemic and pulmonary venous blood pathways were separated by bovine pericardial patch. Consequently, dual pulmonary venous blood flow was created; RUPV and RMPV drained directly or through the intra-atrial tunnel and sinus venous ASD into the LA (Fig. 2b). Pulmonary valve replacement was performed with a $25 \mathrm{~mm}$ Trifecta aortic bioprosthesis valve (St. Jude Medical, Inc., USA). The duration of bypass and aortic cross-clamp was 125 and $96 \mathrm{~min}$, respectively. After an uneventful postoperative course, patient was discharged on postoperative day 6. Postoperative echocardiography demonstrated improvement of D-shaped LV and laminar flow through the SVC and PVs. Postoperative computed tomography showed a well-reconstructed SVC and pulmonary venous pathway without stenosis (Fig. 3).

\section{Discussion}

The exact embryogenesis of RIV remains unknown. The dominant hypothesis is that RIV represents the persistent inferior transverse capillary plexus between the anterior cardinal veins during embryonic development. The descent of the aortic arch and development of the pulmonary artery normally leads to the degeneration of the inferior transverse capillary plexus, explaining the common association of TOF, pulmonary artery hypoplasia, and arch anomaly with RIV [1, 4].
In PAPVR, some PVs drain either into the systemic venous circulation or directly into the right atrium, resulting in a physiologic left-to-right shunt. Patients with hemodynamically insignificant shunts are asymptomatic with absence of right heart failure and conservative management is recommended with close monitoring [5]. However, if a significant left-to-right shunt is left untreated, pulmonary artery hypertension can develop leading to pulmonary vascular occlusive disease, Eisenmenger's syndrome, and biventricular heart failure $[2,3]$. Since our patient had symptoms and right ventricular enlargement, PAPVR repair and pulmonary valve replacement were indicated.

Several procedures have been reported for the repair of PAPVR with high insertion of PVs into the SVC. The Warden procedure or its modifications are preferred, although they have many long-term complications including sinus node dysfunction, SVC or PV obstruction, and supraventricular arrhythmias [2, 3]. RIV is asymptomatic by itself, but RIV in patients with PAPVR to SVC is surgically challenging because a simple Warden procedure is impossible. These patients may experience obstruction of the SVC or innominate vein more commonly after the Warden procedure because anterior mobilization of the innominate vein during the procedure may cause RIV compression by the ascending aorta.

Since our patient was diagnosed with PAPVR at 16 years of age, she had relatively large-sized PVs compared with younger pediatric infants plus dual pulmonary venous blood flow, making it possible and/or easy to repair PAPVR. Due to late diagnosis of PAPVR she have been distressed with right ventricle enlargement and D- 

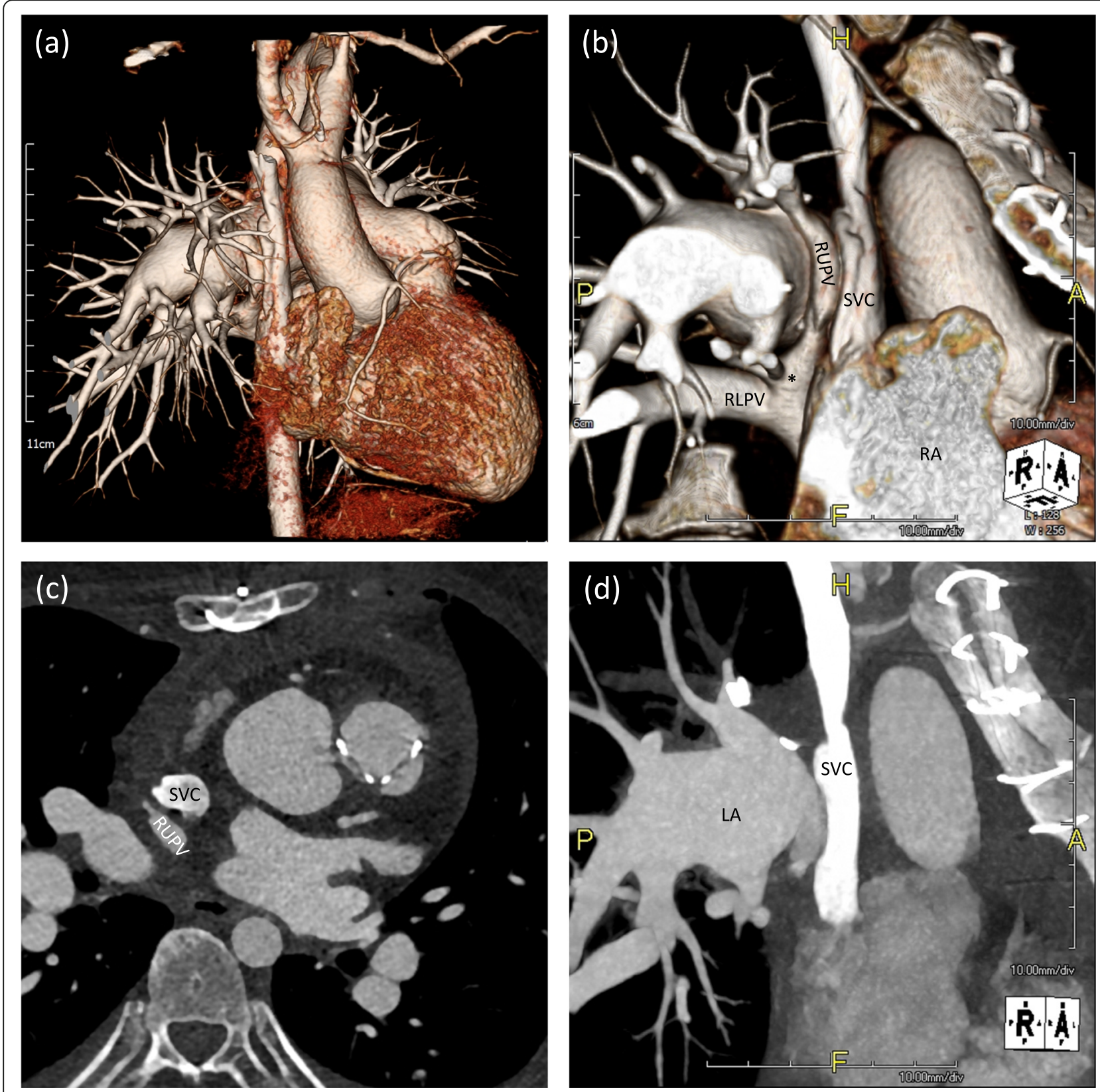

Fig. 3 Postoperative chest computed tomography with (a) 3-dimensional reconstruction and (b) well-constructed SVC and pulmonary veins. Computed tomography demonstrating (c) RUPV and (d) LA separated from SVC. RUPV, right upper pulmonary vein; RMPV (asterisk), right middle pulmonary vein; RLPV, right lower pulmonary vein; SVC, superior vena cava; RA, right atrium; LA, left atrium

shaped LV, perhaps her PVs size might have been too small at the time of the first surgery, making PAPVR repair technically difficult with poor prognosis.

\section{Conclusion}

RIV does not cause symptoms by itself, but its presence in patients with PAPVR may be surgically challenging to repair. We have described a repair technique for SVC and PV reconstruction in patients with PAPVR. Through our case, infants with complex PAPVR, delayed or staged repair of PAPVR could be preferrable till patient grows up to have proper sized PVs to repair.

\section{Abbreviations}

RIV: Retroaortic innominate vein; PAPVR: Partial anomalous pulmonary venous return; TOF: Tetralogy of Fallot; PV: Pulmonary vein; LA: Left atrium; SVC: Superior vena cava; ASD: Atrial septal defect; LV: Left ventricle; RUPV: Right upper pulmonary vein; RMPV: Right middle pulmonary vein

Acknowledgements

Image illustration was performed by college student, Soomin Park. 


\section{Authors' contributions}

$Y L$ conceived the report and wrote the manuscript. JYC was the main surgeon. $Y L$ assisted during the surgery. $H J, Y L$ and $J Y C$ were involved in patient care. HJ revised the manuscript. All authors have approved the final manuscript.

\section{Funding}

Not applicable.

\section{Availability of data and materials}

Not applicable.

\section{Declarations}

Ethics approval and consent to participate

Not applicable.

\section{Consent for publication}

Written informed consent was obtained from the patient's parents for the publication of this case report and the use of any accompanying images.

\section{Competing interests}

The authors declare that they have no competing interests.

Received: 18 October 2020 Accepted: 5 April 2021

Published online: 15 April 2021

\section{References}

1. Kulkarni S, Jain S, Kasar P, Garekar S, Joshi S. Retroaortic left innominate vein - incidence, association with congenital heart defects, embryology, and clinical significance. Ann Pediatr Cardiol. 2008;1(2):139-41. https://doi.org/1 0.4103/0974-2069.43881.

2. Shahriari A, Rodefeld MD, Turrentine MW, Brown JW. Caval division technique for sinus Venosus atrial septal defect with partial anomalous pulmonary venous connection. Ann Thorac Surg. 2006;81(1):224-30. https:// doi.org/10.1016/j.athoracsur.2005.07.015.

3. Agarwal V, Okonta KE, Abubakar U, Gichuhi S. Impact of Warden's procedure on the sinus rhythm: our experience. Heart Lung Circ. 2011; 20(11):718-21. https://doi.org/10.1016/j.hlc.2011.08.004.

4. Leal SMB, Andrade JL, de Souza M, Soares AM, Tavares GMP, Afiune JY, et al. Anomalous subaortic course of the left brachiocephalic (innominate) vein: echocardiographic diagnosis and report of an unusual association. Cardiol Young. 2002;12(2):159-63. https://doi.org/10.1017/S104795110200032X.

5. El-Kersh K, Homsy E, Daniels CJ, Smith JS. Partial anomalous pulmonary venous return: a case series with management approach. Respir Med Case Rep. 2019;27:100833. https://doi.org/10.1016/j.rmcr.2019.100833.

\section{Publisher's Note}

Springer Nature remains neutral with regard to jurisdictional claims in published maps and institutional affiliations. 